\title{
Association of CaMK2A and MeCP2 signaling pathways with cognitive ability in adolescents

Li-Ching Lee ${ }^{1}$, Ming-Tsan Su², Hsing-Ying Huang ${ }^{1}$, Ying-Chun Cho ${ }^{1}$, Ting-Kuang Yeh ${ }^{1,3,4^{*}}$ and Chun-Yen Chang ${ }^{1,4^{*}}$ (iD

\begin{abstract}
The glutamatergic signaling pathway is involved in molecular learning and human cognitive ability. Specific single variants (SNVs, formerly single-nucleotide polymorphisms) in the genes encoding N-methyl-D-aspartate receptor subunits have been associated with neuropsychiatric disorders by altering glutamate transmission. However, these variants associated with cognition and mental activity have rarely been explored in healthy adolescents. In this study, we screened for SNVs in the glutamatergic signaling pathway to identify genetic variants associated with cognitive ability. We found that SNVs in the subunits of ionotropic glutamate receptors, including GRIA1, GRIN1, GRIN2B, GRIN2C, GRIN3A, GRIN3B, and calcium/calmodulin-dependent protein kinase lla (CaMK2A) are associated with cognitive function. Plasma CaMK2A level was correlated positively with the cognitive ability of Taiwanese senior high school students. We demonstrated that elevating CaMK2A increased its autophosphorylation at T286 and increased the expression of its downstream targets, including GluA1 and phosphor- GluA1 in vivo. Additionally, methyl-CpG binding protein 2 (MeCP2), a downstream target of CaMK2A, was found to activate the expression of CaMK2A, suggesting that MeCP2 and CaMK2A can form a positive feedback loop. In summary, two members of the glutamatergic signaling pathway, CaMK2A and MeCP2, are implicated in the cognitive ability of adolescents; thus, altering the expression of CaMK2A may affect cognitive ability in youth.
\end{abstract}

Keywords: Glutamatergic signaling pathway, Single-nucleotide variant (SNV), Methyl-CpG binding protein 2 (MeCP2), Calcium/calmodulin-dependent protein kinase lla (CaMK2A), Cognitive function

\section{Introduction}

N-methyl-D-aspartate receptors (NMDARs) are ionotropic glutamate receptors crucial for neuronal communication, which plays a central role in learning, memory, and synaptic development. NMDARs form tetrameric complexes that consist of two glutamate ionotropic receptor NMDA type subunit 1 (GluN1) subunits and two GluN2 or GluN3 subunits [1-3]. Although NMDARs are widely expressed throughout the central nervous system (CNS), their number, localization, and subunit

\footnotetext{
*Correspondence: Tkyeh@ntnu.edu.tw; changcy@ntnu.edu.tw ${ }^{1}$ Science Education Center and Graduate Institute of Science Education, National Taiwan Normal University, No. 88, Sec. 4, Ting-Chou Rd., Taipei 11677, Taiwan, Republic of China

Full list of author information is available at the end of the article
}

composition are strictly regulated and differ by cell and synapse. All NMDAR subunits contain modular domains that are responsible for controlling distinct functions. All of the ionotropic glutamate receptor subunits, including the seven GluNs, share a common membrane topology; however, the GluN1 isoforms and GluN2 subunits exhibit developmental and regional variations [4-8]. Approximately 2 decades ago, the GluN3A and GluN3B subunits were the last NMDAR subunits to be cloned [9, 10]. GluN3A expression is low before birth, peaks during early postnatal life, and decreases to low levels in adulthood [11]. By contrast, GluN3B subunit expression is low original author(s) and the source, provide a link to the Creative Commons licence, and indicate if changes were made. The images or other third party material in this article are included in the article's Creative Commons licence, unless indicated otherwise in a credit line to the material. If material is not included in the article's Creative Commons licence and your intended use is not permitted by statutory regulation or exceeds the permitted use, you will need to obtain permission directly from the copyright holder. To view a copy of this licence, visit http://creativecommons.org/licenses/by/4.0/. The Creative Commons Public Domain Dedication waiver (http://creativeco mmons.org/publicdomain/zero/1.0/) applies to the data made available in this article, unless otherwise stated in a credit line to the data. 
in early life but increases progressively through adulthood [12].

Synaptic proteins play a crucial role in synaptic activity and dendritic spine morphogenesis, and variations in synaptic proteins lead to cognitive deficits [13]. Because cognitive ability directly affects intellectual capacity, these proteins are associated with youth academic achievement [14]. Of all the genes involved in cognitive function, members of the glutamatergic signaling pathway are the most interesting [15]. Glutamate is a major excitatory neurotransmitter involved in learning and memory, long-term potentiation (LTP), and synaptic plasticity [16]. In neurons, glutamate binds to and activates ionotropic receptors (e.g., NMDA) and $\alpha$-amino-3-hydroxy-5-methyl-4-isoxazolepropionic acid receptors (AMPARs) and mediates $\mathrm{Ca}^{2+}$ transport, thus activating intracellular signaling cascades to alter synaptic efficacy and induce LTP [17].

A signaling pathway activated by ionotropic receptor-mediated $\mathrm{Ca}^{2+}$ influx involves $\mathrm{Ca}^{2+} /$ calmodulin (CaM)-dependent protein kinase II (CaMKII), a serine/ threonine kinase enriched at excitatory synapses and postsynaptic densities [18]. Upon binding with $\mathrm{Ca}^{2+}$ / CaM, CaMKII phosphorylates numerous substrates responsible for LTP, including voltage- and ligandgated $\mathrm{Ca}^{2+}$ channels, cAMP-response element-binding protein, extracellular signal-regulated kinase (ERK), and voltage-gated sodium channels [19]. After initial activation by $\mathrm{Ca}^{2+}$-bound CaM, CaMKII autophosphorylates at Thr286/287, thus enhancing its binding affinity for $\mathrm{Ca}^{2+} / \mathrm{CaM}$ and inducing $\mathrm{Ca}^{2+} / \mathrm{CaM}$-independent autonomous phosphorylation [20]. This autonomous kinase activity of CaMKII has been hypothesized as providing biochemical memory storage for LTP [18, 21]. Blockade of the autophosphorylation of CaMK2A (Thr 286), a forebrain-enriched CaMKII isoform, in knock-in mice expressing phospho-dead CaMKII ${ }^{T 286 A}$ variant proteins impaired LTP, sLTP, and spatial learning and memory [22].

Several recent studies have provided novel insights into the synaptic mechanisms of pathological pathways and have demonstrated that de novo variations in CaMK2A disrupt the function of synaptic proteins [23]. For example, a Glu831 to Val (CaMK2A ${ }^{E 831 V}$ ) variation in the CaMK2A catalytic domain reduces both CaMK2A substrate phosphorylation and regulatory autophosphorylation. Additionally, CaMK2A ${ }^{E 831 V}$ may inhibit the phosphorylation of CaMK2A in a dominant-negative manner [24]. Loss of function from $C a M K 2 A$ variation $\left(\right.$ CaMK2 $\mathrm{A}^{\text {H477Y }}$ ) causes growth delay and seizures in humans [25]. Related studies of two de novo variants in CaMK2A and CaMK2B have demonstrated that Thr286/ Thr287 plays a pivotal role in neuronal plasticity $[23,26]$.
Activated CaMK2A targets dendritic spines and postsynaptic density through interactions with various CaMKIIassociated proteins, including GluN2B NMDAR subunits [27].

CaMKII also functions in the nucleus through nuclear $\mathrm{Ca}^{2+}$ signaling. One principal substrate of CaMKII is methyl-CpG binding protein 2 (MeCP2). During neuronal activity and the subsequent $\mathrm{Ca}^{2+}$ influx, CaMKII phosphorylates MeCP2 at S421 [28, 29]. This neuronal activity-induced phosphorylation is essential for numerous neuronal functions and neurodevelopment [30]. MeCP2 phosphorylation at various sites regulates numerous target genes, including brain-derived neurotrophic factor $(B D N F)$, ras-related GTP-binding protein 3d (Rab3d), vesicle-associated membrane protein 3(Vamp3), and cell adhesion molecule (CADM3). The neuronal activity-induced phosphorylation of MeCP2 might function as a molecular switch regulating the dynamic expression of neuronal genes [31].

$\mathrm{MeCP} 2$ is an $\mathrm{X}$-linked global transcription regulator that binds to methylated sites in DNA, and its dysfunction is implicated in Rett syndrome (RTT) and MeCP2 duplication syndrome (MDS). Well-defined mouse models of both syndromes have resulted in learning and memory impairment [32-34]. Apart from the neuropathological lesions caused by MeCP2-related disorders, the mechanisms through which MeCP2 affects learning and cognitive ability (e.g., intelligence quotient) remain unknown. Research on the underlying pathophysiological mechanisms of RTT and MDS advanced our understanding of MeCP2 functions in the nervous system [35]. After screening adolescents for genetic and epigenetic factors associated with cognitive ability, we previously reported that multiple epigenetic biomarkers regulating MeCP2 homeostasis are associated with academic performance [36]. Because components of glutamatergic signaling, including, CaMK2A, NMDARs, and AMPARs, are essential for appropriate synaptic development and plasticity, and their disruption leads to cognitive deficits, we speculated that subtle and chronic alterations in these genes might affect the cognitive ability of students.

Signaling modulators, including CaMK2A and MeCP2, impair cognitive function in many neuropsychiatric disorders [37-39]. Although the molecular mechanisms underlying disease progression have been determined, the roles of these genes in the cognitive function of healthy adolescents have not been investigated. To identify genetic and epigenetic factors associated with adolescent cognitive ability, we demonstrated that multiple epigenetic biomarkers regulate $\mathrm{MeCP} 2$ homeostasis and are associated with academic performance [36]. In this study, we investigated genetic factors associated with youth cognitive ability. We discovered that 
single-nucleotide variants (SNVs) in CaMK2A and the subunits of ionotropic glutamate receptors, including GRIN1, GRIN2B, GRIN2C, GRIN3A, GRIN3B, GRIA1, and GRID1, are associated with student cognitive function. Furthermore, we discovered that CaMK2A levels were elevated in the peripheral blood samples of senior high school students with superior reasoning skills. Elevated CaMK2A increased the pCaMK2A and GluA1 in cells. Moreover, a downstream target of CaMK2A, $\mathrm{MeCP} 2$ could increase the expression of CaMK2A, suggesting the CaMK2A and MeCP2 could form an autoregulatory positive feedback signal transduction loop. We believed that alteration in the expression of CaMK2A might affect the cognitive ability of adolescents through altering the expression of the components of the glutamatergic signaling pathway.

\section{Materials and methods Participants}

A total of 832 students ( 269 males and 563 females, aged $16.3 \pm 0.5$ years) from three senior high schools (one each in Southern, Central, and Northern Taiwan) were recruited. This study was approved by the Institutional Review Board of National Taiwan University Hospital (Research Ethics identifier: NCT00713570). The volunteers and their parents were explicitly informed, and written consent was obtained.

\section{Genetic screening, variation analysis, and bioinformatics} DNA samples from 20 healthy participants were first genotyped in a pilot study. SNVs with a minor allele frequency of $>5 \%$ were selected. The selected SNVs were then genotyped for all participants. Genotyping was conducted through DNA sequencing of relevant polymerase chain reaction (PCR) products using Prism_ BigDye Terminator v3.1 Cycle Sequencing Ready Reaction Kits and a Prism_ 3730 Genetic Analyzer (Applied Biosystems, Foster City, CA, USA) following manufacturer instructions.

\section{Cognitive ability assessments}

Cognitive ability was assessed with the Multiple Aptitude Test Battery (MAT) [40, 41]. A Chinese version of the MAT was created from the Differential Aptitude Test [41]. The revised MAT was standardized for measuring the cognitive ability of Taiwanese adolescents [42] and comprises eight subtests: verbal reasoning, numerical ability, mechanical reasoning, perceptual speed and accuracy, spatial relations, abstract reasoning, verbal comprehension, and grammar and language. The test contains 496 items and requires approximately $80 \mathrm{~min}$ to complete; consistency reliability ranges from 0.5 to 0.9 .

\section{Blood samples and enzyme-linked immunosorbent assay}

Blood samples were collected from the participants by using ethylenediaminetetraacetic acid (EDTA) as an anticoagulant and placed on ice. The samples were then centrifuged at $4{ }^{\circ} \mathrm{C}$ for $10 \mathrm{~min}$ at $3000 \mathrm{~g}$. Plasma was collected and stored at $-80{ }^{\circ} \mathrm{C}$ until use. Platelets were removed through centrifugation for $10 \mathrm{~min}$ at $10000 \mathrm{~g}$. CaMK2A levels were measured using a quantitative enzyme-linked immunosorbent assay (ELISA) kit following the manufacturer's instructions (LifeSpan BioSciences, Inc. WA, USA).

\section{CaMK2A cDNA constructs and cloning}

CaMK2A mRNA (cDNA clone Mammalian Gene Collection (MGC): 95) was purchased and reverse transcribed to generate CaMK2A cDNA (Bioresource Collection and Research Center, Taiwan). The CaMK2A cDNA was digested with NotI and ApaI restriction endonucleases and cloned with $\mathrm{N}$-terminal-tagged enhanced green fluorescent protein or C-terminal-tagged DsR into a pcDNA/ Flp recombination Target (FRT)/TO cloning vector (Thermo Fisher Scientific Co. MA USA) (Fig. 1).

\section{Cell culture and transfection}

The Flp-In T-REx system was used to stably induce the expression of target genes in the HEK293 and SH-SY5Y cell lines (Invitrogen, Carlsbad, CA, USA). HEK293derived Flp-In host cells were purchased (Flp-In T-REx Cell Line, Invitrogen). The generation of the SH-SY5Yderived Flp-In host cells was described previously [43]. In brief, the two cell lines were cotransfected with a pOG44 plasmid (constitutively expressing Flp recombinase) and a pcDNA5/FRT/TO-CaMK2A or pcDNA5/FRT/TOMeCP2 plasmid following the supplier's instructions. These stable cell lines were cultured in a medium containing $5 \mathrm{mg} / \mathrm{mL}$ blasticidin and $100 \mathrm{mg} / \mathrm{mL}$ hygromycin.

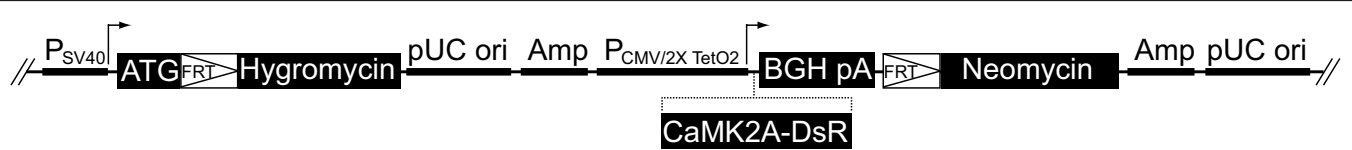

Fig. 1 Schematic outline (not to scale) of the Flp-ln ${ }^{\mathrm{TM}}$ stable cell lines with inducible expression of CaMK2A-DsR fused gene. The CaMK2A-DsR expression cassette is integrated into a distinct Flp recombination target site and is under the control of the Tet repressor. CaMK2A expression is induced by tetracycline. P: promoter; SV40: simian virus 40; CMV: cytomegalovirus; lacZ: $\beta$-galactosidase ORF, Amp: ampicillin ORF, DsR: DsRed ORF, pUC ori: Replication origin of plasmid pUC, TetO2: Tetracycline operator 2, and BGH pA: Bovine growth hormone polyadenylation signal 
Doxycycline $(1 \mathrm{mg} / \mathrm{mL})$ was added for $2-6$ days to induce CaMK2A and MeCP2 expression.

\section{Western blotting}

Total soluble protein was extracted from the HEK293derived and SH-SY5Y-derived cells treated with $3 \mu \mathrm{M}$ CaM (Bovine brain Millipore Sigma-Aldrich, MO, USA) at designated time points $(0,2,4$, and 6 days) using a buffer containing $50 \mathrm{mM}$ Tris- $\mathrm{HCl}, 150 \mathrm{mM} \mathrm{NaCl}, 1 \mathrm{mM}$ EDTA, $1 \mathrm{mM}$ ethylene glycol-bis( $\beta$-aminoethyl ether)$\mathrm{N}, \mathrm{N}, \mathrm{N}^{\prime}, \mathrm{N}^{\prime}$-tetraacetic acid, $0.1 \%$ SDS, $0.5 \%$ sodium deoxycholate, $1 \%$ Triton $\mathrm{X}-100$, and a protease inhibitor cocktail (Life Technologies [Thermo Fisher Scientific], Carlsbad, CA, USA). After sonication and centrifugation at $15000 \mathrm{~g}$ for $10 \mathrm{~min}$ at $4{ }^{\circ} \mathrm{C}$, protein concentration was determined (Bio-Rad Protein Assay, Hercules, CA, USA) with bovine serum albumin as the standard. Soluble proteins $(25 \mu \mathrm{g})$ were separated through $12 \%$ sodium dodecyl sulfate-polyacrylamide gel electrophoresis (SDS-PAGE). The proteins were electroblotted onto nitrocellulose membranes, which were blocked with $10 \%$ nonfat milk and probed with primary antibodies. The antibodies and dilutions used were as follows: antiMeCP2 (1:2000; GeneTex), anti-pMeCP2 (phospho-S80; 1:1000; GeneTex), anti-CaMK2A (1:1000; GeneTex), anti-pCaMK2A (phospho-T286; 1:1000; GeneTex), antiBDNF (1:2000; GeneTex), anti-GluA1 (1:2000; Abcam, Cambridge, UK), anti-GluA1 (phospho-S831; 1:1000; Abcam), and anti-H3.3B (1:2000; GeneTex) antibodies. Immune complexes were detected using horseradish peroxidase-conjugated goat anti-mouse, goat anti-rabbit (Jackson Immuno Research, West Grove, PA, USA) IgG (1:10,000), and a chemiluminescent substrate (Millipore, Burlington, MA, USA).

\section{Chromatin immunoprecipitation}

The SH-SY5Y-derived cells were treated with formaldehyde (1\% final concentration) for $10 \mathrm{~min}$ at $37{ }^{\circ} \mathrm{C}$ and quenched with $0.125 \mathrm{M}$ glycine for $5 \mathrm{~min}$ at $25^{\circ} \mathrm{C}$. After being washed twice with PBS, the samples were homogenized in lysis buffer (1\% SDS, 10 mM EDTA, 50 mM Tris; $\mathrm{pH}$ 8.1) containing a protease inhibitor (Thermo Fisher Scientific MA, USA). Chromatin was sheared using a Bioruptor sonicator for 35 30-s-ON/30-s-OFF cycles in a $4{ }^{\circ} \mathrm{C}$ water bath. For immunoprecipitation, $150 \mu \mathrm{L}$ of chromatin was diluted at a ratio of 1:10 in chromatin immunoprecipitation (ChIP) dilution buffer (0.01\% SDS, 1.1\% Triton X-100, $1.2 \mathrm{mM}$ EDTA, $16.7 \mathrm{mM}$ Tris- $\mathrm{HCl}$, $167 \mathrm{mM} \mathrm{NaCl} ; \mathrm{pH}$ 8.1). Approximately $7 \%$ of the diluted sample was used as input control. Protein A/G Magnetic Beads (Merck Millipore, MA, USA) were incubated with anti-MeCP2 antibodies (GeneTex) or rabbit IgG overnight at $4{ }^{\circ} \mathrm{C}$ and constantly rotated in a blocking solution
(0.5\% BSA in PBS). After washing and resuspension of the antibody-bead conjugates, the chromatin samples were added to the antibody-bead conjugates and incubated for $16 \mathrm{~h}$ and rotated constantly at $4^{\circ} \mathrm{C}$. After immunoprecipitation, the beads were washed six times $(5 \mathrm{~min}$ each) with buffer (50 mM HEPES-KOH, $500 \mathrm{mM} \mathrm{LiCl}$, 1 mM EDTA, 1\% NP-40, 0.7\% Na-deoxycholate; pH 7.6). and washed with TE buffer $(10 \mathrm{mM}, 1 \mathrm{mM}$ EDTA; $\mathrm{pH}$ 8.1). DNA-proteins complexes were eluted with a $200-\mu \mathrm{L}$ elution buffer (50 mM Tris-HCl, $1 \mathrm{mM}$ EDTA, 1\% SDS; $\mathrm{pH}$ 8.1). The eluted samples were incubated at $65{ }^{\circ} \mathrm{C}$ for $4 \mathrm{~h}$, and the input DNA was diluted in elution buffer (to $200 \mu \mathrm{L}$ ) and processed for cross-link reversal. The samples were then digested sequentially in $0.2 \mu \mathrm{g} / \mathrm{mL}$ RNase A for $2 \mathrm{~h}$ at $37^{\circ} \mathrm{C}$ and $20 \mu \mathrm{g}$ of proteinase $\mathrm{K}$ for $30 \mathrm{~min}$ at $55^{\circ} \mathrm{C}$. The DNA was extracted using the phenol/chloroform/isoamyl alcohol method and subjected to quantitative PCR using the ViiA 7 real-time PCR system (Thermo Fisher Scientific MA, USA) with primer pairs for GRINI, GRIA1, and GRID1.

\section{Statistical analysis}

The associations of genotypes with the participants' cognition (MAT scores) were assessed through analysis of variance (One-way ANOVA). Univariate ANOVA was performed to compare MAT subtest scores among the three genotype groups for each SNV. Significance was set at $p<0.05$. Bonferroni correction was used for multigroup comparisons. Post hoc Scheffe's F testing was performed because of its high statistical power [44]. For each SNV, the participants were assigned to one of three groups based on their genotype, and deviations from the Hardy-Weinberg equilibrium were tested using a chisquared test. Gene-gene interactions were assessed using analysis of covariance. The ANOVAs and inferential statistical analyses were conducted in SPSS version 23.0.

\section{Results}

Gene screening, variation analysis, and bioinformatics

Our previous study discovered that genetic variants in glutamatergic signaling components were associated with the emotions and social behaviors of adolescents [45]. In the present study, 832 10th-grade (269 male; 563 female) volunteers were recruited for the study. DNA samples from 20 healthy participants were genotyped in a pilot study. From the set of candidate genes associated with NMDARs, 174 SNVs were identified using information available in the Entrez Gene (http://www. ncbi.nlm.nih.gov/gene), HapMap (http://www.hapmap. org), and Ensembl (http://www.ensembl.org/Homo_sapie ns) databases. We found that SNVs in genes encoding NMDAR subunits were associated with academic performance and cognitive ability (Table 1 ). The observed 
Table 1 Demographics

\begin{tabular}{lccc}
\hline & Male & Female & $p$ \\
\hline Age (yrs) & $16.8 \pm 0.32^{*}$ & $16.8 \pm 0.30$ & \\
Academic performance & & & \\
BCT & $245.9 \pm 19.69$ & $235.8 \pm 20.61$ & $<0.01$ \\
Cognitive abilities & & & \\
Verbal reasoning & $21.5 \pm 5.31$ & $21.9 \pm 5.16$ & \\
Numerical ability & $11.1 \pm 3.56$ & $10.90 \pm 3.37$ & \\
Mechanical reasoning & $14.3 \pm 3.91$ & $13.3 \pm 3.46$ & $<0.01$ \\
Space relations & $17.1 \pm 4.49$ & $15.4 \pm 4.49$ & $<0.01$ \\
Abstract reasoning & $20.2 \pm 4.81$ & $19.1 \pm 4.95$ & $<0.01$ \\
Verbal comprehension & $21.5 \pm 6.14$ & $22.2 \pm 5.91$ & $<0.05$ \\
Grammar and language usage & $17.9 \pm 5.04$ & $18.5 \pm 5.00$ & $<0.05$ \\
Perceptual speed and accuracy & $67.2 \pm 21.33$ & $68.1 \pm 20.19$ & \\
\hline
\end{tabular}

* Mean ( \pm standard deviation); BCT, basic competency test

genotype distribution for each SNV was consistent with the Hardy-Weinberg equilibrium. Furthermore, the genotype frequencies for each SNV in the study population were consistent with the HapMap-HCB population study results reported by the International HapMap Project.

In total, $26 \mathrm{SNVs}$ with a minor allele frequency greater than $5 \%$ in the pilot study were identified as candidates and used for further genotyping experiments for all 832 volunteers. We discovered that $13 \mathrm{SNVs}$ were significantly associated with cognitive ability (Table 3 ). The participants' background (age, years of education, academic performance; Table 1) and MAT subtest (verbal reasoning, numerical ability, mechanical reasoning, perceptual speed and accuracy, spatial relations, abstract reasoning, verbal comprehension, and grammar and language usage) scores for the genotype groups for each SNV were analyzed through ANOVA (Tables 2 and 3).

NMDARs are glutamate-gated cation channels that are expressed throughout the brain and play an essential role in physiological and pathological processes in the CNS. The spatiotemporal expression of the diverse subunits imparts distinct channel kinetics, permeation, blockage by divalent cations, and sensitivity to endogenous modulators. The GRIN1 rs4880213 variant was significantly associated with perceptual speed and accuracy $(p=0.018)$. The GRIN2B rs1805502 variant was significantly associated with abstract reasoning and grammar and language usage ( $p=0.022$ and $p=0.053)$, and the GRIN2C rs3744215 variant was significantly associated with mechanical reasoning $(p=0.013)$. Two SNVs in GRIN3A (rs10989589 and rs3739722) were significantly associated with verbal comprehension and abstract reasoning $(p=0.017 p=0.033)$. The other six SNVs in GRIN3B were significantly associated with the eight MAT subtest scores as follows. GRIN3B rs2240154 was significantly associated with abstract reasoning $(p=0.012)$. GRIN3B rs4807399was significantly associated with abstract reasoning and grammar and language usage $(p=0.035$ and $p=0.024)$. GRIN3B rs2240157 was significantly associated with abstract reasoning $(p=0.025)$. GRIN3B rs2285906 was significantly associated with mechanical reasoning, abstract reasoning, and perceptual speed and accuracy $(p=0.018, p=0.03$, and $p=0.018)$. GRIN3B rs10417824 was significantly associated with abstract reasoning and perceptual speed and accuracy $(p=0.012$ and $p=0.033)$. GRIN3B rs10401454 was significantly associated with scores on five of the eight MAT subtests, namely the verbal reasoning, spatial relations, abstract reasoning, verbal comprehension, and grammar and language usage $(p=0.005, p=0.043, p=0.008$, $p=0.006$, and $p=0.003$, respectively) scores, as listed in Table 3.

\section{Plasma CaMK2A level was positively correlated with cognitive abilities}

To assess cognitive ability using the MAT, only students without physical or mental disorders were included in our study. The GRIA1 rs548294 and CaMK2A (rs2241694) SNVs were highly associated with cognitive ability, prompting us to study how they affect gene function and how these genes affect cognitive ability. The CaMK2A (rs2241694) variant was significantly associated with perceptual speed and accuracy $(p=0.041)$. To address this, 120 students were selected for the study based on their MAT scores. Sixty students with MAT scores higher than $80 \%$ were included in a high-cognitive ability group, and 60 students with MAT scores lower than $12 \%$ were considered a low-cognitive ability group. Plasma CaMK2A levels were measured using ELISA. The plasma CaMK2A levels of the students with high and low cognitive ability were 529 and $271 \mathrm{pg} / \mathrm{mL}$, respectively. Thus, plasma CaMK2A was positively correlated with the cognitive ability of Taiwanese senior high school students (Table 4).

\section{Relationship between identified SNVs and plasma CaMK2A levels}

In correlating SNVs and CaMK2 levels with the cognitive ability of adolescents, we found that GRIN3B rs4807399 with the CT genotype was significantly associated with higher plasma CaMK2A levels and cognitive ability (Table 5). Additionally, GRIN3B rs10417824 with the A allele (AA, AT) was significantly associated with higher plasma CaMK2A levels and cognitive 
Table 2 Genotype distributions and chromosome locations of SNVs

\begin{tabular}{|c|c|c|c|c|c|}
\hline Gene & SNP ID & Allele/genotype & Subjects & Chromosome region & Genotype frequency \\
\hline \multirow[t]{3}{*}{ GRIN1 } & & & & $9 q 34.3$ & \\
\hline & rs4880213 & $\mathrm{CC} / \mathrm{CT} / \mathrm{TT}$ & $124 / 368 / 340$ & & $0.15 / 0.44 / 0.41$ \\
\hline & rs11146020 & $\mathrm{CC} / \mathrm{CG} / \mathrm{GG}$ & $565 / 239 / 28$ & & $0.68 / 0.29 / 0.03$ \\
\hline \multirow[t]{6}{*}{ GRIN2B } & & & & $12 \mathrm{p} 12$ & \\
\hline & rs3764028 & CC/CG/GG & 250/396/186 & & $0.30 / 0.48 / 0.22$ \\
\hline & rs1806201 & $\mathrm{AA} / \mathrm{AG} / \mathrm{GG}$ & 223/438/171 & & $0.27 / 0.53 / 0.20$ \\
\hline & rs1805247 & $\mathrm{AA} / \mathrm{AG} / \mathrm{GG}$ & $608 / 204 / 20$ & & $0.73 / 0.25 / 0.02$ \\
\hline & rs1805502 & $\mathrm{AA} / \mathrm{AG} / \mathrm{GG}$ & $608 / 203 / 20$ & & $0.73 / 0.24 / 0.03$ \\
\hline & rs7301328 & $\mathrm{AA} / \mathrm{AC} / \mathrm{CC}$ & $148 / 397 / 287$ & & $0.18 / 0.48 / 0.34$ \\
\hline \multirow[t]{2}{*}{ GRIN2C } & & & & $17 q 25$ & \\
\hline & rs3744215 & $\mathrm{AA} / \mathrm{AC} / \mathrm{CC}$ & $143 / 423 / 266$ & & $0.17 / 0.51 / 0.32$ \\
\hline \multirow[t]{5}{*}{ GRIN3A } & & & & $9 q 34.1$ & \\
\hline & rs10989591 & $\mathrm{CC} / \mathrm{CT} / \mathrm{TT}$ & $738 / 90 / 4$ & & 0.89/0.11/0.01 \\
\hline & rs10989589 & $\mathrm{CC} / \mathrm{CT} / \mathrm{TT}$ & $527 / 265 / 40$ & & 0.63/0.32/0.05 \\
\hline & rs3739722 & $\mathrm{CC} / \mathrm{CT} / \mathrm{TT}$ & $508 / 287 / 37$ & & $0.61 / 0.35 / 0.04$ \\
\hline & rs62000403 & TT/AT/AA & 708/115/9 & & $0.85 / 0.14 / 0.01$ \\
\hline \multirow[t]{12}{*}{ GRIN3B } & & & & 19p13.3 & \\
\hline & rs2240154 & $\mathrm{CC} / \mathrm{CT} / \mathrm{TT}$ & $254 / 405 / 173$ & & $0.31 / 0.49 / 0.21$ \\
\hline & rs35592366 & $C C / A C / A A$ & 627/191/14 & & $0.75 / 0.23 / 0.02$ \\
\hline & rs55646937 & GG/AG/AA & $562 / 231 / 39$ & & 0.58/0.28/0.05 \\
\hline & rs12978900 & $\mathrm{TT} / \mathrm{CT} / \mathrm{TT}$ & $697 / 133 / 2$ & & 0.84/0.16/0.01 \\
\hline & rs4807399 & $\mathrm{CC} / \mathrm{CT} / \mathrm{TT}$ & 707/119/6 & & 0.86/0.14/0.01 \\
\hline & rs2240157 & $\mathrm{CC} / \mathrm{CT} / \mathrm{TT}$ & 207/413/212 & & $0.25 / 0.50 / 0.26$ \\
\hline & rs10666583 & $\mathrm{MM} / \mathrm{Mm} / \mathrm{mm}$ & $730 / 98 / 4$ & & 0.88/0.12/0.01 \\
\hline & rs2240158 & $\mathrm{CC} / \mathrm{CT} / \mathrm{TT}$ & $597 / 214 / 21$ & & $0.72 / 0.26 / 0.03$ \\
\hline & rs2285906 & GG/AG/AA & $626 / 183 / 23$ & & $0.75 / 0.22 / 0.03$ \\
\hline & rs10417824 & TT/AT/AA & $362 / 355 / 115$ & & $0.23 / 0.22 / 0.08$ \\
\hline & rs10401454 & $\mathrm{CC} / \mathrm{CG} / \mathrm{GG}$ & $622 / 163 / 47$ & & $0.75 / 0.23 / 0.02$ \\
\hline \multirow[t]{2}{*}{ GRIAI } & & & & $5 q 33.2$ & \\
\hline & rs548294 & $\mathrm{CC} / \mathrm{CT} / \mathrm{TT}$ & $374 / 372 / 86$ & & $0.45 / 0.45 / 0.10$ \\
\hline \multirow[t]{2}{*}{ GRID1 } & & & & $10 q 23.1-2$ & \\
\hline & rs3814614 & $\mathrm{GG} / \mathrm{AG} / \mathrm{AA}$ & $522 / 266 / 42$ & & 0.63/0.32/0.05 \\
\hline \multirow[t]{2}{*}{ CaMK2A } & & & & $5 q 32$ & \\
\hline & rs2241694 & GG/AG/AA & $580 / 235 / 16$ & & 0.70/0.28/0.02 \\
\hline
\end{tabular}

ability. Elevated plasma CaMK2A levels might not reflect an increase in activity in the CNS. We address this issue in the Section "Discussion".

\section{CaMK2A upregulation triggers autophosphorylation signaling cascade}

To assess the effect of CaMK2A upregulation in vivo, quantitative immunoblotting was performed using a human-derived neuroblastoma SH-SY5Y cell line because it has been used to study the relations of epigenetic biomarkers with academic performance and neuronal disorders associated with neurocognitive disorders [36, 46-50]. CaMK2A autophosphorylation increased proportionately with its expression, plateauing 2 days after СaMK2A upregulation CaMK2A expression persisted through day 6, whereas pCaMK2A had been slightly downregulated by day 6 (Fig. 2B). Additionally, GluAl, a component of the AMPAR, is phosphorylated by CaMK2 at S831. GluA1 was concomitantly upregulated with $\mathrm{pCaMK} 2 \mathrm{~A}$ upregulation on days 2-4 and had been downregulated by day 6. CaMK2 and GluA1 phosphorylation were both increased, suggesting that CaMK2A upregulation might initiate CaMK2 phosphorylation and phosphorylate downstream targets such as GluA1 (Fig. 2C). 


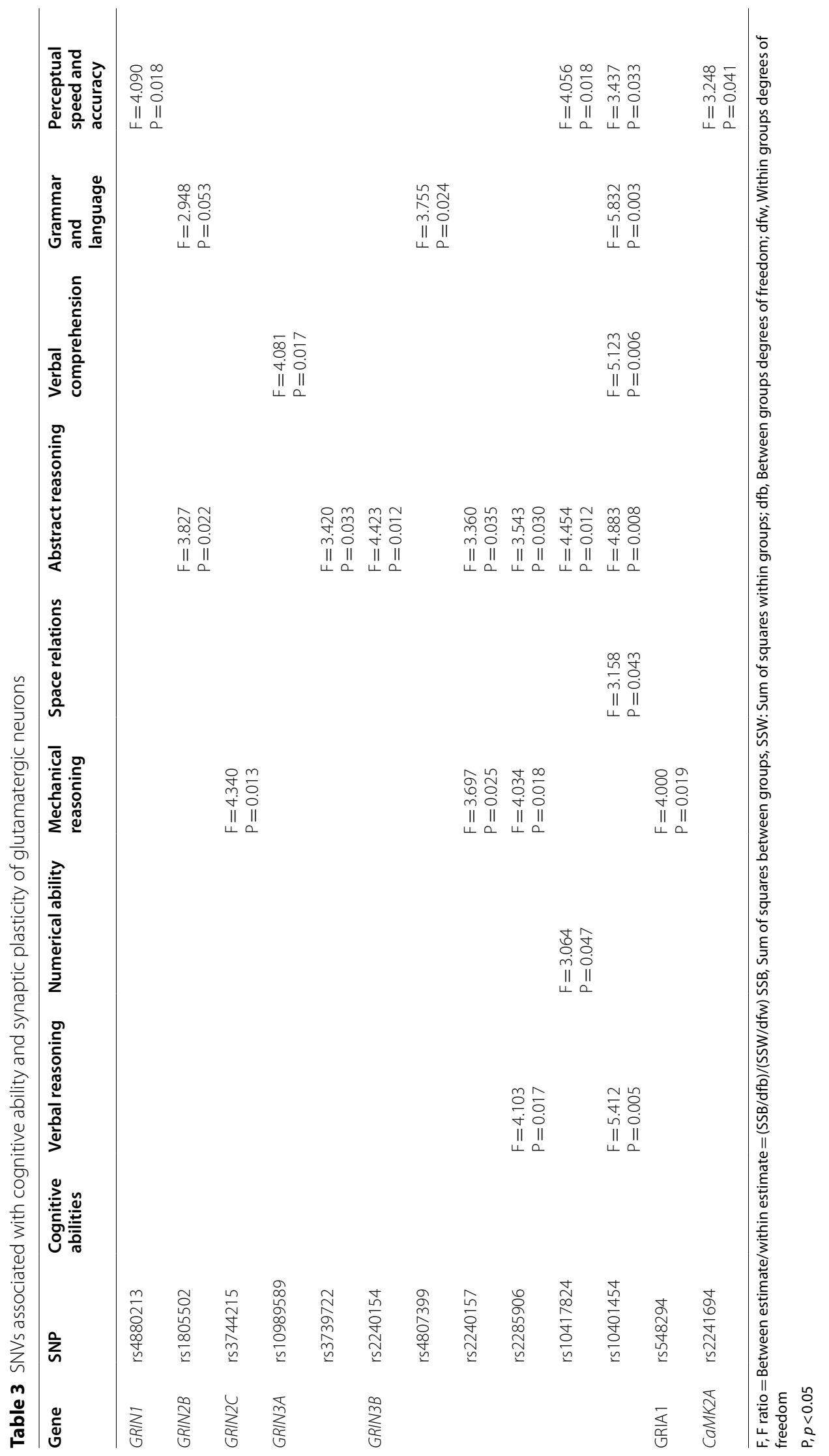


Table 4 Plasma CaMK2A is positively correlated with cognitive ability

\begin{tabular}{lllll}
\hline & HMAT group $(\boldsymbol{n}=\mathbf{6 0})$ & LMAT group $(\boldsymbol{n}=\mathbf{6 0})$ & $\boldsymbol{T}$ & $\boldsymbol{p}$ \\
\hline CaMK2A Plasma level $(\mathrm{pg} / \mathrm{ml})$ & $523.3(189.5)(\mathrm{pg} / \mathrm{ml})$ & $272.1(214.3)(\mathrm{pg} / \mathrm{ml})$ & 6.80 & $<0.001$ \\
\hline
\end{tabular}

* Mean values (standard deviation)

HMAT, Higher Multiple Aptitude Test; LMAT, Lower Multiple Aptitude Test

${ }^{* * *} p<0.001 ; n=120$, Student's $t$ test

\section{MeCP2 is involved in CaMK2A-mediated phosphorylation regulation}

We previously reported the involvement of a homeostatic regulatory control mechanism of $\mathrm{MeCP} 2$, similar to that of CaMKII, in both Rett syndrome and synaptic plasticity [46]. CaMKII autophosphorylation is essential for LTP induction and memory consolidation, and MeCP2 is a direct target of CaMKII; therefore, we investigated whether MeCP2 is involved in an autoregulatory loop that activates CaMKII and increases CaMKII autophosphorylation. Quantitative immunoblotting revealed that CaMK2A and phospho-MeCP2 (S80) were significantly upregulated 2 days after $\mathrm{MeCP} 2$ induction in stably transfected SH-SY5Y cells. The elevated expression persisted through day 6 after MeCP2 induction. This finding indicates that $\mathrm{CaMK} 2 \mathrm{~A}$ and $\mathrm{MeCP} 2$ may form a positive feedback loop. Furthermore, BDNF, a downstream target of $\mathrm{MeCP} 2$, was significantly upregulated upon MeCP2 overexpression in SH-SY5Y cells, indicating that phospho-MeCP2 was released by the BDNF promoter, thereby facilitating BDNF expression (Fig 3).

\section{GRIA1 and GRID1 promoter regions are direct targets of MeCP2}

To determine the correlation between the identified SNVs and their potential regulation of promoter binding regulation we performed ChIP to investigate whether $\mathrm{MeCP} 2$ binds to the promoter regions encompassed by
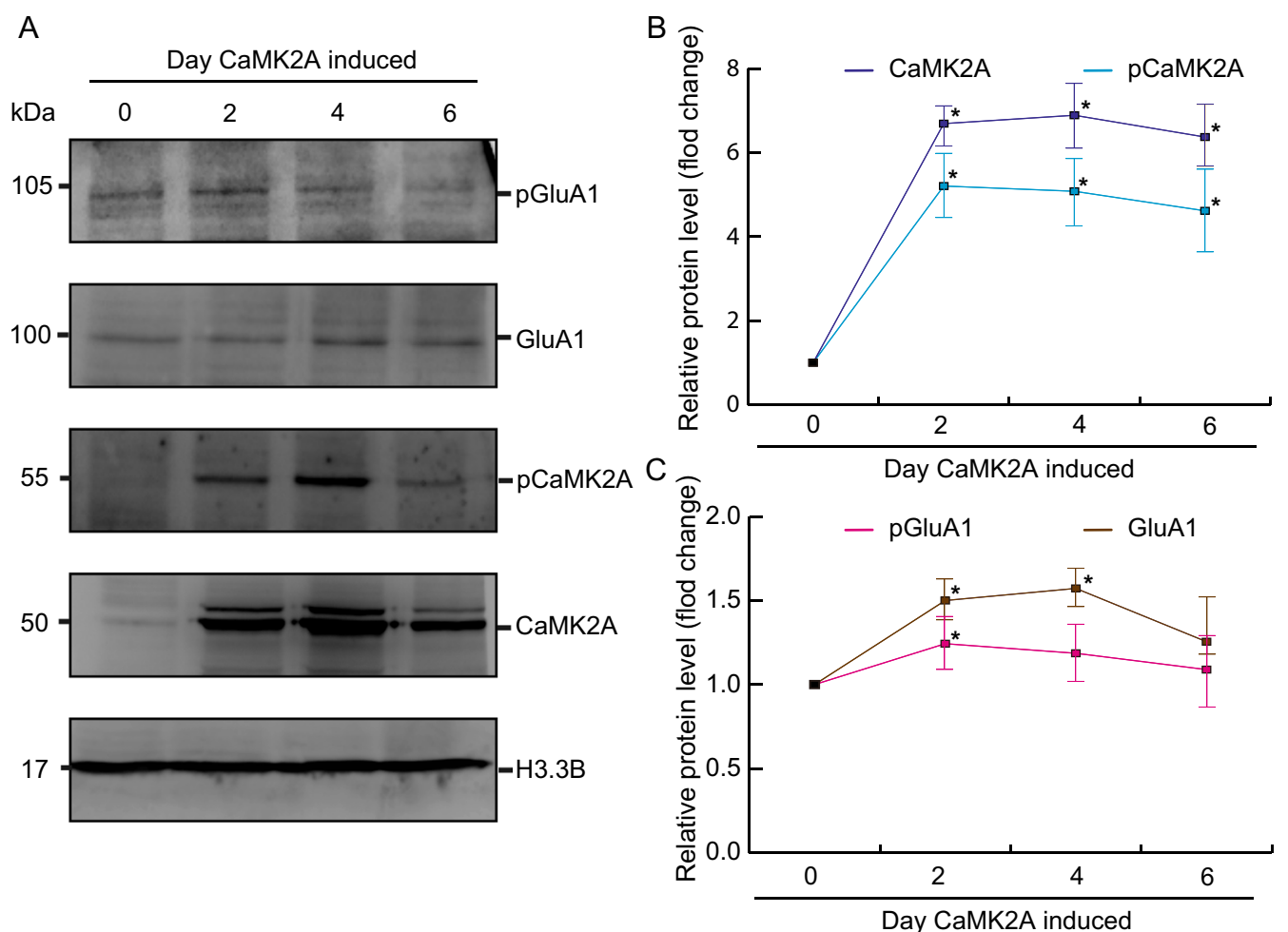

Fig. 2 Increased CaMK2A activated autophosphorylation. Total soluble protein from HEK293-derived cells was harvested at 2, 4, and 6 days after induction of CaMK2A expression with doxycycline. A Representative immunoblots displaying CaMK2A, phospho-CaMK2A (T286), GluA1, and phospho-GluA1 (S831) expression. H3.3B was considered the loading control. B, C Autophosphorylation of CaMK2A and phosphorylation of GluA1 increased after CaMK2A induction. Quantification of relative protein levels. Data are presented as mean \pm standard deviation. ${ }^{*} p<0.05, n=5$, Student's $t$ test 
Table 5 Association of GRIN family genotypes with plasma CaMK2A levels and cognitive ability

\begin{tabular}{|c|c|c|c|c|c|c|}
\hline & & $\mathrm{N}$ & Mean & SD & $\mathrm{F}$ & $\mathbf{P}$ \\
\hline \multicolumn{7}{|l|}{ GRIN3A_rs3739722 } \\
\hline \multirow[t]{3}{*}{ CaMK2A Conc } & $\mathrm{CC}$ & 70 & 401.98 & 240.01 & 3.041 & $>0.05$ \\
\hline & CT & 43 & 424.45 & 224.42 & & \\
\hline & $\mathrm{TT}$ & 7 & 190.62 & 223.68 & & \\
\hline \multirow[t]{3}{*}{ Cognitive ability } & CC & 70 & 45.76 & 42.57 & 4.891 & $0.009^{*}$ \\
\hline & CT & 43 & 56.40 & 40.61 & & \\
\hline & $\mathrm{TT}$ & 7 & 5 & 2.45 & & \\
\hline \multicolumn{7}{|l|}{ GRIN3B_rs2240154 } \\
\hline \multirow[t]{3}{*}{ CaMK2A Conc } & CC & 44 & 427.66 & 258.17 & 0.686 & $>0.05$ \\
\hline & CT & 56 & 371.80 & 222.85 & & \\
\hline & TT & 20 & 404.31 & 234.75 & & \\
\hline \multirow[t]{3}{*}{ Cognitive ability } & CC & 44 & 61.68 & 40.35 & 5.219 & $0.007^{*}$ \\
\hline & CT & 56 & 42.34 & 41.88 & & \\
\hline & TT & 2 & 28.90 & 37.58 & & \\
\hline \multicolumn{7}{|l|}{ GRIN3B_rs4807399 } \\
\hline \multirow[t]{3}{*}{ CaMK2A Conc } & CC & 98 & 374.67 & 239.60 & 4.299 & $0.016^{*}$ \\
\hline & CT & 20 & 528.64 & 184.27 & & \\
\hline & TT & 2 & 216.90 & 220.70 & & \\
\hline \multirow[t]{3}{*}{ Cognitive ability } & CC & 98 & 42.75 & 41.58 & 3.377 & $0.037^{*}$ \\
\hline & CT & 20 & 69.05 & 37.89 & & \\
\hline & TT & 2 & 46.50 & 64.35 & & \\
\hline \multicolumn{7}{|l|}{ GRIN3B_2240157 } \\
\hline \multirow[t]{3}{*}{ CaMK2A Conc } & CC & 42 & 429.98 & 262.68 & 0.679 & $>0.05$ \\
\hline & CT & 55 & 373.07 & 221.50 & & \\
\hline & $\mathrm{TT}$ & 23 & 397.67 & 230.31 & & \\
\hline \multirow[t]{3}{*}{ Cognitive ability } & $\mathrm{CC}$ & 42 & 62.29 & 40.31 & 5.35 & $0.006^{*}$ \\
\hline & CT & 55 & 43.02 & 41.93 & & \\
\hline & $\mathrm{TT}$ & 23 & 29.61 & 37.79 & & \\
\hline \multicolumn{7}{|l|}{ GRIN3B_rs2285906 } \\
\hline \multirow[t]{3}{*}{ CaMK2A Conc } & AA & 3 & 342.32 & 278.78 & 1.081 & $>0.05$ \\
\hline & AG & 41 & 441.34 & 240.59 & & \\
\hline & GG & 76 & 376.35 & 234.66 & & \\
\hline \multirow[t]{3}{*}{ Cognitive ability } & AA & 3 & 35.33 & 49.23 & 4.032 & $0.020^{*}$ \\
\hline & AG & 41 & 61.93 & 39.58 & & \\
\hline & GG & 76 & 39.71 & 41.55 & & \\
\hline \multicolumn{7}{|l|}{ GRIN3B_rs10417824 } \\
\hline \multirow[t]{3}{*}{ CaMK2A Conc } & AA & 18 & 457.39 & 270.92 & 4.686 & $0.011^{*}$ \\
\hline & AT & 60 & 441.06 & 220.98 & & \\
\hline & TT & 42 & 310.19 & 226.06 & & \\
\hline \multirow[t]{3}{*}{ Cognitive ability } & AA & 18 & 70.94 & 35.94 & 8.571 & $0.000^{*}$ \\
\hline & AT & 60 & 53.13 & 42.42 & & \\
\hline & $\pi T$ & 42 & 28.52 & 36.80 & & \\
\hline \multicolumn{7}{|c|}{ GRIN3B_rs10401454 } \\
\hline \multirow[t]{3}{*}{ CaMK2A Conc } & CC & 75 & 371.39 & 223.99 & 1.489 & $>0.05$ \\
\hline & CG & 35 & 454.98 & 259.31 & & \\
\hline & GG & 10 & 394.64 & 248.75 & & \\
\hline \multirow[t]{3}{*}{ Cognitive ability } & CC & 75 & 39.09 & 41.74 & 4.391 & $0.014^{*}$ \\
\hline & CG & 35 & 57.51 & 40.78 & & \\
\hline & GG & 10 & 71.80 & 34.07 & & \\
\hline
\end{tabular}

${ }^{*} p$ value $<0.05$ 

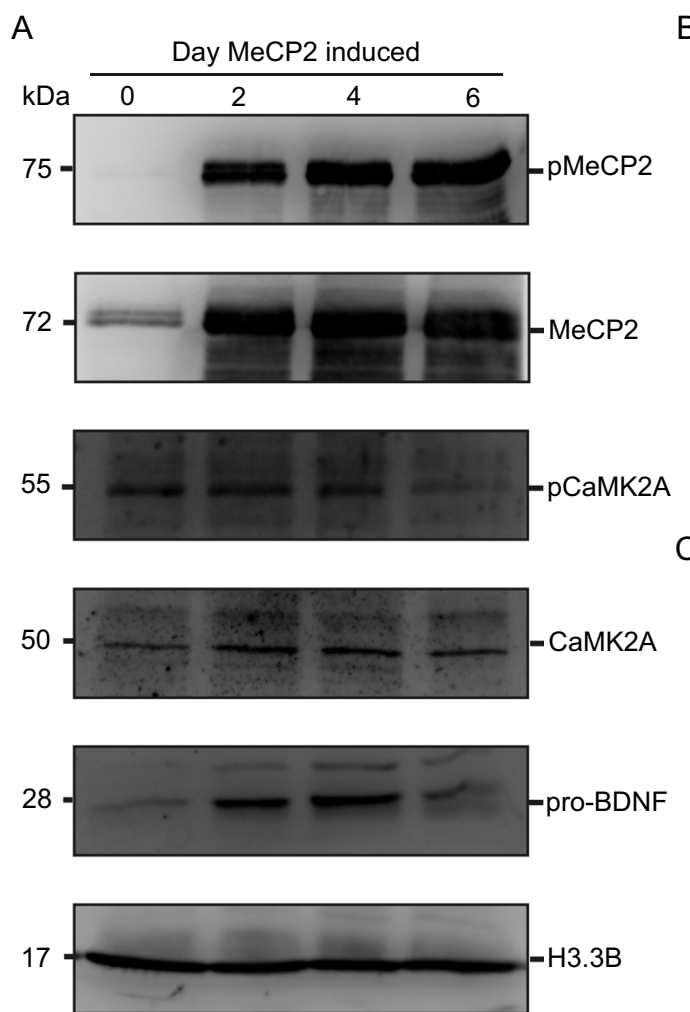

B

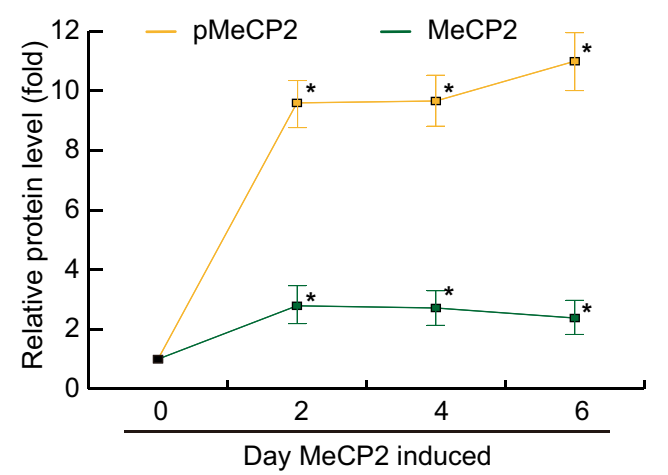

C

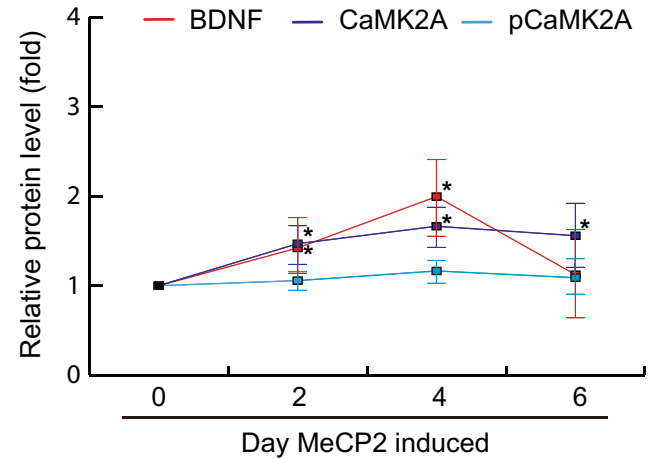

Fig. $3 \mathrm{MeCP} 2$ is involved in CaMK2A-mediated phosphorylation. Total soluble protein from stably transfected SH-SY5Y cells was harvested at 2, 4 , and 6 days after induction of MeCP2 expression with doxycycline. A Representative immunoblots displaying phospho-MeCP2 (S80), MeCP2, phospho-CaMK2A (T286), CaMK2A, and pro-BDNF expression. H3.3B was considered the loading control. B, C Quantification of relative protein expression levels. Data are presented as mean \pm standard deviation. ${ }^{*} p<0.05, n=5$, Student's $t$ test

these SNVs (e.g., GRIA1 promoter 548294, GRID1 promoter 3814614, and GRIN1 promoter 4880213). An anti-MeCP2 antibody could pull down the promoters of GRIA1 and GRID1 in SH-SY5Y neurons, indicating that MeCP2 directly regulates GRIA1 and GRID1 (Fig. 4). By contrast, MeCP2 could not bind to the GRIN1 promoter (Fig. 4). Furthermore, the binding of MeCP2 to the GRIA1 and GRID1 promoters was time-dependent, indicating that GRIA1 and GRID1 are direct downstream targets of MeCP2 (Fig. 4).

\section{Discussion}

In this study, we investigated the correlations of the genetic variations and expression of genes involved in synaptic plasticity with the cognitive function of senior high school students. To identify genetic variants related to cognitive ability, we studied members of the NMDAdependent AMPAR trafficking cascade, including GRIN1, GRIN2B, GRIN2C, GRIN3A, GRIN3B, GRIA1, and $C a M K 2 A$, because the functions of glutamate receptors and CaMKII are involved in neural plasticity and memory [51]. The repeated action-potential firing and subsequent calcium influx induce autonomous activation of CaMKII, which is essential for memory formation. The activation of CaMKII is also closely linked to the NMDAR, whose main function is synaptic restructuring and long-term memory formation [52, 53]. Plasma CaMK2A levels were positively associated with the cognitive ability of students. Using cultured cell systems, we discovered alterations in the levels of the aforementioned proteins, including $\mathrm{MeCP} 2, \mathrm{pMeCP} 2, \mathrm{CaMK} 2 \mathrm{~A}$, pCaMK2A, GluA1, and pGluA1. We believe that using a simpler cultured cell system could aid in uncovering the role of these elementary building blocks of learning and memory in more complex organisms.

The students in our study were physically healthy and from homogeneous socioeconomic areas; therefore, our results may not apply more broadly to a heterogeneous population. Additionally, although our effective sample size was small, we detected the associations between SNVs in glutamatergic system genes and the cognitive ability of Taiwanese senior high school students. Specifically, variants of CaMK2A (rs2241694) and several glutamatergic system genes including GRIA1, GRIN1, GRIN2, 

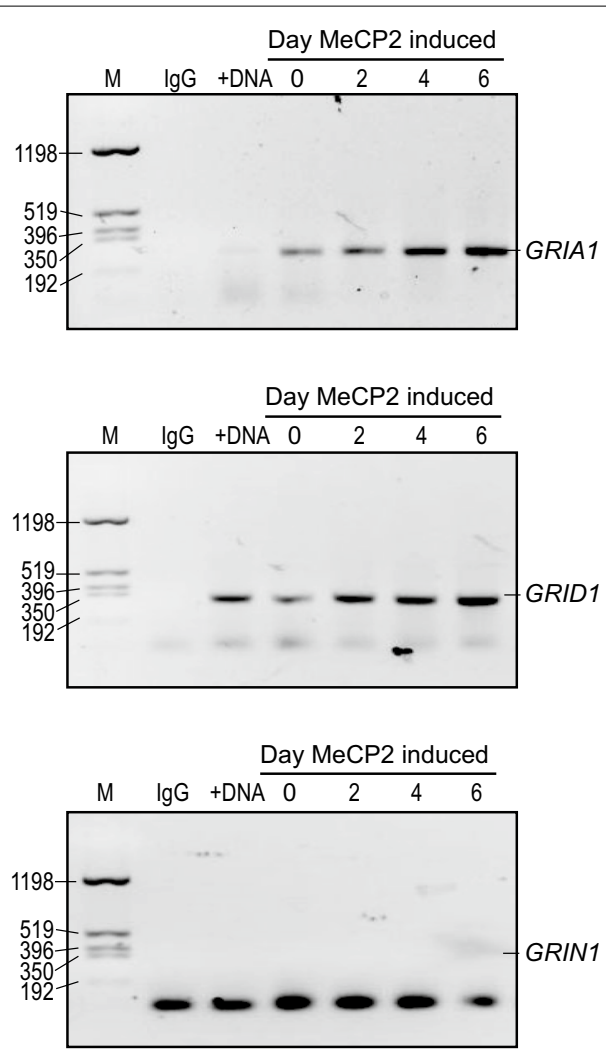

Fig. 4 MeCP2 binds to GRIA1 and GRID1 promoters. ChIP was performed using anti-MeCP2 antibodies on sheared chromatin from SH-SY5Y neuroblastoma cells expressing MeCP2 on days $0,2,4$, and 6. Purified DNA from immunoprecipitated chromatin was amplified using optimized primers for the promoters (GRIA1, GRIDI, and GRIN1). Molecular weight markers are on the left in bases. Normal rabbit lgG was used as a negative immunoprecipitation control. +DNA: Purified chromosomal DNA, used as a positive control

GRIN3A, and GRIN3B were associated with cognitive ability. Of all $174 \mathrm{SNVs}$ in our genetic association study, those of GRIN2A and GRIN2D were excluded because of their low minor allele frequency $(<5 \%)$. This finding suggests that the major alleles for the GRIN2A and GRIN2D SNVs might be conserved in the Han Chinese population. Furthermore, the GRIN2C rs3744215 SNV was significantly associated with abstract reasoning. In addition to the cerebellum, GluN2C expression was also detected in several first- and higher-order thalamic nuclei, vestibular nuclei, and parvalbumin-positive interneurons [54]. Lesions in the cerebellum, especially in the posterior lobes, can impair executive function, including planning, abstract reasoning, and working memory [55]. Moreover, a recent meta-analysis revealed that the subdivisions of the thalamus are associated with different cognitive functions [56]. These findings suggest that cerebellumenriched GluN2C might function in abstract reasoning.
Consistent with our findings, several GRIN3B variants were previously associated significantly with cognitive function [57]. GRIN3B, an unconventional member of the NMDAR family, complexes with the GluN1 and GluN2 subunits and modulates $\mathrm{Ca}^{2+}$ permeability and membrane trafficking $[58,59]$. However, stimulation of unconventional receptors, such as GluN3B, may compete against conventional NMDARs (GluN1/GluN2) for synaptic depotentiation in response to subsequent synaptic stimulation [60]. This metaplasticity is thought to be involved in LTP, long-term depression, and memory storage. Further research to examine how the GRIN3B variations affect the function of glutamatergic receptors and the cognitive ability of students is warranted.

Using ELISA, we discovered that students who performed well on the MAT had higher plasma CaMK2A, whereas students who scored poorly on the MAT had lower plasma CaMK2A. CaMK2A concentrations quantified through mass spectrometry and ELISA are compatible because both are in picogram per liter ranges (https:// www.proteinatlas.org/ENSG00000070808-CAMK2A/ blood). CaMK2A is expressed mostly in the CNS, adrenal gland, stomach, kidneys, liver, and bone marrow (https:// www.proteinatlas.org/ENSG00000070808-CAMK2A/tissue). It can also be detected in neutrophils and memory $B$ cells in the circulatory system. Although we do not know the source of plasma CaMK2A or how it is secreted into serum, ELISA is sufficiently sensitive for measuring it in blood samples. Because blood samples are more accessible than neuronal tissue samples, plasma proteins and peptides exported from the brain in blood samples would be ideal for practical exploration of the biomarkers that affect cognitive ability in young people.

The expression of pCaMK2A (Thr286), GluA1, and pGluA1 (Ser831) were increased was elevated in the stably transfected HEK293 cells expressing CaMK2A, suggesting that CaMK2A could initiate an autophosphorylation cascade, thereby activating the downstream target genes (Fig. 2). Additionally, MeCP2, a downstream target of CaMK2A, and BDNF can be activated by MeCP2 in SH-SY5Y cells (Fig. 3). Although we are unsure whether $\mathrm{MeCP} 2$, a transcription regulator that binds to methylated DNA, activates CaMK2A directly, our result demonstrates that CaMK2A and $\mathrm{MeCP} 2$ could form an autoregulatory loop. Notably, a 1.5 -fold increase occurred in CaMK2A, but pCaMK2A was not increased in SH-SY5Y cells expressing MeCP2 (Fig. 3). The CaMK2A increase may be insufficient to initiate its autophosphorylation. However, a $\mathrm{Ca}^{2+}$ influx may be initially required to trigger CaMK2A phosphorylation, and that cytosolic $\mathrm{Ca}^{2+}$ might have been insufficient to initiate CaMK2A autophosphorylation in MeCP2-expressing cells. We believe that a sufficient 


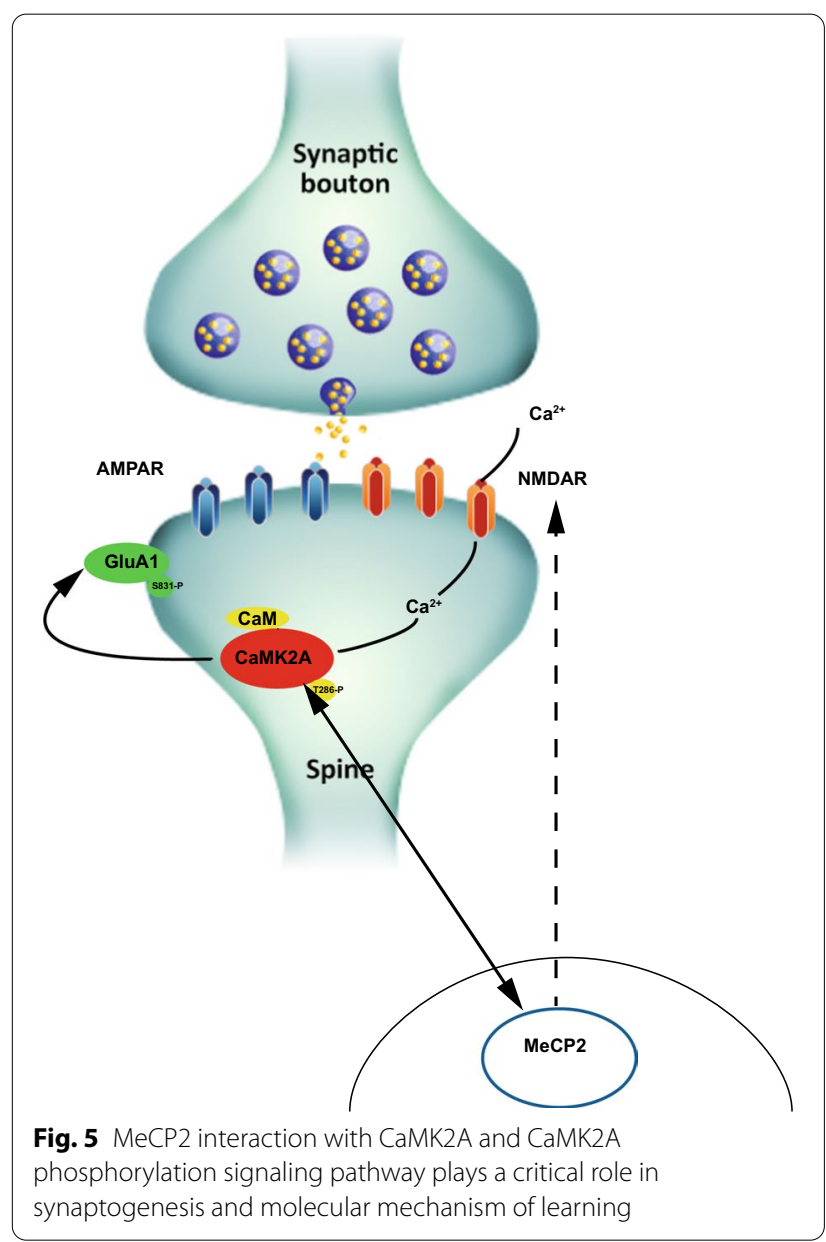

amount of the upregulated CaMK2A may be autophosphorylated when a $\mathrm{Ca}^{2+}$ influx is triggered by neuronal activity.

In summary, we found that SNVs in CaMK2A and subunits of ionotropic glutamate receptors, including GRIA1, GRIN1, GRIN2, and GRIN3, were associated with the cognitive function of students (Tables 1,2,3). The levels of CaMK2A were elevated in the peripheral blood samples of senior high school students with strong reasoning skills, especially in those with GRIN3B variants. These results indicate that the primary function of the CaMK2A phosphorylation signaling pathway is critical in synaptogenesis and the molecular mechanism of learning (Fig. 5). The physiological and pathological roles of CaMK2A have attracted substantial attention due to their involvement in synaptic plasticity. Our SH-SY5Y-derived CaMK2A model is an appropriate system to study the associations of synaptogenesis, LTP, and long-term depression and the cognitive function of students.

\section{Limitations}

Although the students were of similar ages and had similar educational backgrounds, the male students outperformed the female students in basic competency test $(\mathrm{BCT})$, numerical ability, mechanical reasoning, spatial relations, and abstract reasoning, whereas female students performed better in verbal comprehension and grammar and language usage (Table 1). We cannot attribute the differences in cognition to sex alone, because human cognition is highly complex and may be influenced by the environment, culture, and individual experience [61]. Moreover, because we could not assess these factors quantitatively, over-interpretation of results and speculation regarding the cause of the results would be inappropriate.

We found that plasma CaMK2A levels were correlated with the cognitive ability of students (Table 4). To further assess the consequences of CaMK2A upregulation in vivo, we quantified the expression levels of several components of glutamatergic signaling in a human-derived SH-SY5Y cell line (Figs. 2 and 3). Although the cultured neuroblastoma cells enabled quick assessment, noninvasive monitoring of gene expression in the brain would be more informative.

\section{Abbreviations}

ANOVA: Analysis of variance; AMPAR: a-Amino-3-hydroxy-5-methyl-4isoxazolepropionic acid receptor; $\mathrm{BCT}$ : Basic competency test; BDNF: Brain-derived neurotrophic factor; Cam: Calmodulin; CaMK2A: Calcium/ calmodulin-dependent protein kinase lla; CNS: Central nervous system; EDTA: Ethylenediaminetetraacetic acid; ELISA: Enzyme-linked immunosorbent assay; GRINs: Glutamate ionotropic receptor N-methyl-D-aspartate type subunits genes (GRIN1, GRIN2A-D, GRIN3A,3B); GluA1: Glutamate ionotropic receptor a-amino-3-hydroxy-5-methyl-4-isoxazolepropionic acid type subunit 1; GluD1: Glutamate ionotropic receptor delta type subunit 1; GluN1: Glutamate ionotropic receptor type subunit 1; GluN2B: Glutamate ionotropic receptor $\mathrm{N}$-methyl-D-aspartate type subunit 2B; GluN2C: Glutamate ionotropic receptor $\mathrm{N}$-methyl-D-aspartate type subunit 2C; GluN3A: Glutamate ionotropic receptor N-methyl-D-aspartate type subunit 3A; GluN3B: Glutamate ionotropic receptor N-methyl-D-aspartate type subunit 3B; LTP: Long-term potentiation; MAT: Multiple Aptitude Test Battery; MeCP2: Methyl-CpG binding protein 2; NMDAR: N-methyl-D-aspartate receptor; SNV: Single-nucleotide variant.

\section{Acknowledgements}

The authors are grateful to all those who participated in the study. This manuscript was edited by Wallace Academic Editing.

\section{Authors' contributions}

LCL contributed to the study's conception, design, and data analysis and drafted the article. MTS contributed to the study's conception and design and revised the paper. HYH contributed to the study's operation and data acquisition. YCC was involved in data analysis. CYC was involved in the study's conception and design and revised the manuscript. TKY contributed to the study's conception, design, and data analysis and revised the paper. All authors read and approved the final manuscript.

\section{Funding}

This work was supported by the National Science Council of Taiwan under the contracts MOST 107-2511-H-003-010-MY3, MOST 108-2511-H-003-059, and MOST 107-2634-F-008-003 and financially supported by the Institute for Research Excellence in Learning Sciences of National Taiwan Normal University 
from The Featured Areas Research Center Program within the framework of the Higher Education Sprout Project by the Ministry of Education of Taiwan. This work was also supported partially by grants (MOST 109-2321-B038-001 and MOST 109-2320-B-003-009) to MT Su received from the Ministry of Science and Technology.

\section{Availability of data and materials}

The data and materials that support the findings of this study are available from the corresponding author upon reasonable request.

\section{Declarations}

\section{Ethics approval and consent to participate}

All participants provided written informed consent before participation. The study was approved by the National Taiwan University Hospital Research Ethics Committee in Taiwan (Research Ethics identifier: NCT00713570) and all study procedures followed the Ministry of Science and Technology in Taiwan.

\section{Consent for publication}

Not applicable.

\section{Competing of interests}

The authors declare that they have no conflict of interest.

\section{Author details}

${ }^{1}$ Science Education Center and Graduate Institute of Science Education, National Taiwan Normal University, No. 88, Sec. 4, Ting-Chou Rd., Taipei 11677, Taiwan, Republic of China. ${ }^{2}$ Department of Life Science, National Taiwan Normal University, Taipei, Taiwan. ${ }^{3}$ Institute of Marine Environment Science and Technology, National Taiwan Normal University, Taipei, Taiwan. ${ }^{4}$ Department of Earth Science, National Taiwan Normal University, Taipei, Taiwan.

\section{Received: 14 May 2021 Accepted: 13 September 2021}

Published online: 04 October 2021

\section{References}

1. Paoletti P, Neyton J. NMDA receptor subunits: function and pharmacology. Curr Opin Pharmacol. 2007;7:39-47.

2. Bard L, Groc L. Glutamate receptor dynamics and protein interaction: lessons from the NMDA receptor. Mol Cell Neurosci. 2011;48:298-307.

3. Flores-Soto ME, Chaparro-Huerta V, Escoto-Delgadillo M, Vazquez-Valls E, González-Castañeda RE, Beas-Zarate C. Structure and function of NMDAtype glutamate receptor subunits. Neurologia. 2012;27:301-10.

4. Laurie DJ, Seeburg PH. Ligand affinities at recombinant N-methyl-Daspartate receptors depend on subunit composition. Eur J Pharmacol. 1994;268:335-45.

5. Paupard MC, Friedman LK, Zukin RS. Developmental regulation and cellspecific expression of $\mathrm{N}$-methyl-D-aspartate receptor splice variants in rat hippocampus. Neuroscience. 1997;79:399-409.

6. Watanabe M, Inoue Y, Sakimura K, Mishina M. Developmental changes in distribution of NMDA receptor channel subunit mRNAs. NeuroReport. 1992;3:1138-40.

7. Akazawa C, Shigemoto R, Bessho Y, Nakanishi S, Mizuno N. Differential expression of five $\mathrm{N}$-methyl-D-aspartate receptor subunit mRNAs in the cerebellum of developing and adult rats. J Comp Neurol. 1994;347:150-60.

8. Monyer H, Burnashev N, Laurie DJ, Sakmann B, Seeburg PH. Developmental and regional expression in the rat brain and functional properties of four NMDA receptors. Neuron. 1994;12:529-40.

9. Ciabarra AM, Sullivan JM, Gahn LG, Pecht G, Heinemann S, Sevarino KA. Cloning and characterization of chi-1: a developmentally regulated member of a novel class of the ionotropic glutamate receptor family. J Neurosci. 1995; 15:6498-508.

10. Nishi M, Hinds H, Lu HP, Kawata M, Hayashi Y. Motoneuron-specific expression of NR3B, a novel NMDA-type glutamate receptor subunit that works in a dominant-negative manner. J Neurosci. 2001;21:Rc185.
11. Wee KS, Zhang Y, Khanna S, Low CM. Immunolocalization of NMDA receptor subunit NR3B in selected structures in the rat forebrain, cerebellum, and lumbar spinal cord. J Comp Neurol. 2008;509:118-35.

12. Low CM, Wee KS. New insights into the not-so-new NR3 subunits of $\mathrm{N}$-methyl-D-aspartate receptor: localization, structure, and function. Mol Pharmacol. 2010;78:1-11.

13. Penzes P, Cahill ME, Jones KA, VanLeeuwen JE, Woolfrey KM. Dendritic spine pathology in neuropsychiatric disorders. Nat Neurosci. 2011;14:285-93.

14. Bueno D. Genetics and learning: how the genes influence educational attainment. Front Psychol. 2019;10:1622.

15. Maiti P, Manna J, Ilavazhagan G, Rossignol J, Dunbar GL. Molecular regulation of dendritic spine dynamics and their potential impact on synaptic plasticity and neurological diseases. Neurosci Biobehav Rev. 2015;59:208-37.

16. Ip JPK, Mellios N, Sur M. Rett syndrome: insights into genetic, molecular and circuit mechanisms. Nat Rev Neurosci. 2018;19:368-82.

17. Vose LR, Stanton PK. Synaptic plasticity, metaplasticity and depression. Curr Neuropharmacol. 2017;15:71-86.

18. Lisman J, Yasuda R, Raghavachari S. Mechanisms of CaMKII action in long-term potentiation. Nat Rev Neurosci. 2012;13:169-82.

19. Rafa-Zabłocka K, Kreiner G, Bagińska M, Nalepa I. The influence of CaMKII and ERK phosphorylation on BDNF changes observed in mice selectively devoid of CREB in serotonergic or noradrenergic neurons. Pharmacol Rep. 2019;71:753-61.

20. Swulius MT, Waxham MN. Ca(2+)/calmodulin-dependent protein kinases. Cell Mol Life Sci. 2008;65:2637-57.

21. Vigil FA, Giese KP. Calcium/calmodulin-dependent kinase II and memory destabilization: a new role in memory maintenance. J Neurochem. 2018;147:12-23.

22. Giese KP, Fedorov NB, Filipkowski RK, Silva AJ. Autophosphorylation at Thr286 of the alpha calcium-calmodulin kinase II in LTP and learning. Science. 1998;279:870-3.

23. Akita T, Aoto K, Kato M, Shiina M, Mutoh H, Nakashima M, Kuki I, Okazaki S, Magara S, Shiihara T, et al. De novo variants in CAMK2A and CAMK2B cause neurodevelopmental disorders. Ann Clin Transl Neurol. 2018;5:280-96.

24. Stephenson JR, Wang X, Perfitt TL, Parrish WP, Shonesy BC, Marks CR, Mortlock DP, Nakagawa T, Sutcliffe JS, Colbran RJ. A novel human CAMK2A mutation disrupts dendritic morphology and synaptic transmission, and causes ASD-related behaviors. J Neurosci. 2017;37:2216-33.

25. Chia PH, Zhong FL, Niwa S, Bonnard C, Utami KH, Zeng R, Lee H, Eskin A, Nelson SF, Xie WH, et al. A homozygous loss-of-function CAMK2A mutation causes growth delay, frequent seizures and severe intellectual disability. Elife. 2018. https://doi.org/10.7554/eLife.32451.

26. Küry S, van Woerden GM, Besnard T, Proietti Onori M, Latypova X, Towne MC, Cho MT, Prescott TE, Ploeg MA, Sanders S, et al. De novo mutations in protein kinase genes CAMK2A and CAMK2B cause intellectual disability. Am J Hum Genet. 2017;101:768-88.

27. Hell JW. CaMKII: claiming center stage in postsynaptic function and organization. Neuron. 2014;81:249-65.

28. Buchthal B, Lau D, Weiss U, Weislogel JM, Bading H. Nuclear calcium signaling controls methyl-CpG-binding protein 2 (MeCP2) phosphorylation on serine 421 following synaptic activity. J Biol Chem. 2012;287:30967-74.

29. Zhou Z, Hong EJ, Cohen S, Zhao WN, Ho HY, Schmidt L, Chen WG, Lin Y, Savner E, Griffith EC, et al. Brain-specific phosphorylation of MeCP2 regulates activity-dependent Bdnf transcription, dendritic growth, and spine maturation. Neuron. 2006;52:255-69.

30. Li H, Zhong X, Chau KF, Williams EC, Chang Q. Loss of activity-induced phosphorylation of MeCP2 enhances synaptogenesis, LTP and spatial memory. Nat Neurosci. 2011;14:1001-8.

31. Chao HT, Zoghbi HY. The yin and yang of MeCP2 phosphorylation. Proc Natl Acad Sci U S A. 2009;106:4577-8.

32. Samaco RC, McGraw CM, Ward CS, Sun Y, Neul JL, Zoghbi HY. Female Mecp2(+/-) mice display robust behavioral deficits on two different genetic backgrounds providing a framework for pre-clinical studies. Hum Mol Genet. 2013;22:96-109.

33. Veeraragavan S, Wan YW, Connolly DR, Hamilton SM, Ward CS, Soriano S, Pitcher MR, McGraw CM, Huang SG, Green JR, et al. Loss of MeCP2 in the 
rat models regression, impaired sociability and transcriptional deficits of Rett syndrome. Hum Mol Genet. 2016;25:3284-302.

34. Gulmez Karaca K, Brito DVC, Zeuch B, Oliveira AMM. Adult hippocampal MeCP2 preserves the genomic responsiveness to learning required for long-term memory formation. Neurobiol Learn Mem. 2018;149:84-97.

35. Karaca GK, Brito DVC, Oliveira AMM. MeCP2: a critical regulator of chromatin in neurodevelopment and adult brain function. Int J Mol Sci. 2019;20:4577

36. Lee LC, Su MT, Cho YC, Lee-Chen GJ, Yeh TK, Chang CY. Multiple epigenetic biomarkers for evaluation of students' academic performance. Genes Brain Behav. 2019;18:e12559.

37. Katz DM, Menniti FS, Mather RJ. N-Methyl-D-aspartate receptors, ketamine, and Rett syndrome: something special on the road to treatments? Biol Psychiatry. 2016;79:710-2.

38. Ogundele OM, Lee CC. CaMKlla expression in a mouse model of NMDAR hypofunction schizophrenia: Putative roles for IGF-1R and TLR4. Brain Res Bull. 2018;137:53-70.

39. Bach S, Ryan NM, Guasoni P, Corvin AP, El-Nemr RA, Khan D, Sanfeliu A, Tropea D. Methyl-CpG-binding protein 2 mediates overlapping mechanisms across brain disorders. Sci Rep. 2020:10:22255.

40. Bennett GK, Seashore HG, Wesman AG. The differential aptitude tests: an overview. J Couns Dev. 2011;35:81-91.

41. Liu IM. Multiple aptitude test battery. J Psychol Chin Soc. 2003;9:103-20.

42. Yeh TK, Cho YC, Yeh TC, Hu CY, Lee LC, Chang CY. An exploratory analysis of the relationship between cardiometabolic risk factors and cognitive/academic performance among adolescents. Biomed Res Int. 2015:2015:520619.

43. Lee LC, Chen CM, Wang HC, Hsieh HH, Chiu IS, Su MT, Hsieh-Li HM, Wu CH, Lee GC, Lee-Chen GJ, Lin JY. Role of the CCAAT-binding protein NFY in SCA17 pathogenesis. PLoS One. 2012;7:e35302.

44. Klockars AJ, Hancock GR. Scheffé's more powerful F-protected Post Hoc procedure. J Edu Behav Stat. 2000;25:13-9.

45. Lee LC, Cho YC, Lin PJ, Yeh TC, Chang CY, Yeh TK. Influence of genetic variants of the N-Methyl-D-aspartate receptor on emotion and social behavior in adolescents. Neural Plast. 2016;2016:6851592.

46. de Medeiros LM, De Bastiani MA, Rico EP, Schonhofen P, Pfaffenseller B, Wollenhaupt-Aguiar B, Grun L, Barbé-Tuana F, Zimmer ER, Castro MAA, et al. Cholinergic differentiation of human neuroblastoma SH-SY5Y cell line and its potential use as an in vitro model for Alzheimer's disease studies. Mol Neurobiol. 2019:56:7355-67.

47. Xicoy H, Wieringa B, Martens GJ. The SH-SY5Y cell line in Parkinson's disease research: a systematic review. Mol Neurodegener. 2017:12:10.

48. Mi Y, Qi G, Fan R, Qiao Q, Sun Y, Gao Y, Liu X. EGCG ameliorates highfat- and high-fructose-induced cognitive defects by regulating the IRS/AKT and ERK/CREB/BDNF signaling pathways in the CNS. Faseb J. 2017:31:4998-5011.
49. Barai P, Raval N, Acharya S, Acharya N. Neuroprotective effects of Bergenia ciliata on NMDA induced injury in SH-SY5Y cells and attenuation of cognitive deficits in scopolamine induced amnesia in rats. Biomed Pharmacother. 2018;108:374-90

50. Martínez MA, Rodríquez JL, Lopez-Torres B, Martínez M, Martínez-Larrañaga MR, Maximiliano JE, Anadón A, Ares I. Use of human neuroblastoma SH-SY5Y cells to evaluate glyphosate-induced effects on oxidative stress, neuronal development and cell death signaling pathways. Environ Int. 2020:135:105414.

51. Chang JY, Parra-Bueno P, Laviv T, Szatmari EM, Lee SR, Yasuda R. CaMKII autophosphorylation is necessary for optimal integration of $\mathrm{Ca}(2+)$ signals during LTP Induction, but not maintenance. Neuron. 2017;94:800808.e804.

52. Morris RG. NMDA receptors and memory encoding. Neuropharmacology. 2013;74:32-40

53. Sanhueza M, Lisman J. The CaMKII/NMDAR complex as a molecular memory. Mol Brain. 2013;6:10.

54. Ravikrishnan A, Gandhi PJ, Shelkar GP, Liu J, Pavuluri R, Dravid SM. Regionspecific expression of NMDA receptor GluN2C subunit in parvalbuminpositive neurons and astrocytes: analysis of GluN2C expression using a novel reporter model. Neuroscience. 2018;380:49-62.

55. Schmahmann JD, Sherman JC. The cerebellar cognitive affective syndrome. Brain. 1998;121(Pt 4):561-79.

56. Antonucci LA, Penzel N, Pigoni A, Dominke C, Kambeitz J, Pergola G. Flexible and specific contributions of thalamic subdivisions to human cognition. Neurosci Biobehav Rev. 2021;124:35-53.

57. Lin YT, Hsieh MH, Liu CC, Hwang TJ, Chien YL, Hwu HG, Liu CM. A recentlydiscovered NMDA receptor gene, GRIN3B, is associated with duration mismatch negativity. Psychiatry Res. 2014;218:356-8.

58. Pérez-Otaño I, Larsen RS, Wesseling JF. Emerging roles of GluN3-containing NMDA receptors in the CNS. Nat Rev Neurosci. 2016;17:623-35.

59. Kumar A. NMDA receptor function during senescence: implication on cognitive performance. Front Neurosci. 2015;9:473.

60. Rozeboom AM, Queenan BN, Partridge JG, Farnham C, Wu JY, Vicini S, Pak DT. Evidence for glycinergic GluN1/GluN3 NMDA receptors in hippocampal metaplasticity. Neurobiol Learn Mem. 2015;125:265-73.

61. Jäncke L. Sex/gender differences in cognition, neurophysiology, and neuroanatomy. F1000Res. 2018:7:805.

\section{Publisher's Note}

Springer Nature remains neutral with regard to jurisdictional claims in published maps and institutional affiliations.
Ready to submit your research? Choose BMC and benefit from:

- fast, convenient online submission

- thorough peer review by experienced researchers in your field

- rapid publication on acceptance

- support for research data, including large and complex data types

- gold Open Access which fosters wider collaboration and increased citations

- maximum visibility for your research: over 100M website views per year

At BMC, research is always in progress.

Learn more biomedcentral.com/submissions 